\title{
Optimal dose determination of enerisant (TS-091) for patients with narcolepsy: two randomized, double-blind, placebo-controlled trials
}

\author{
Yuichi Inoue ${ }^{1,2^{*}}$, Makoto Uchiyama ${ }^{3,4}$, Hideo Umeuchi ${ }^{5}$, Koichi Onishi ${ }^{5}$, Hiroki Ogo ${ }^{5}$, Iwao Kitajima ${ }^{5}$,
} Isao Matsushita ${ }^{5}$, Izumi Nishino ${ }^{5}$ and Naohisa Uchimura ${ }^{6}$

\begin{abstract}
Background: The histamine $\mathrm{H} 3$ receptor has emerged as one of the most promising targets of novel pharmacotherapy for narcolepsy. Studies now aim to investigate the optimal dose of enerisant, a novel H3 antagonist/inverse agonist, for the treatment of excessive daytime sleepiness in patients with narcolepsy.

Methods: We conducted two phase 2, fixed-dose, double-blind, randomized, placebo-controlled trials in patients with narcolepsy. The first phase 2 study (Study 1 ) was conducted to investigate the efficacy and safety of enerisant at dosages of 25, 50, and $100 \mathrm{mg} /$ day administered for 3 weeks based on the results of a phase 1 study conducted on healthy volunteers. The primary endpoint was mean sleep latency in maintenance of wakefulness test (MWT), and the secondary endpoint was the total score on the Epworth Sleepiness Scale (ESS). The dosages of enerisant in the second phase 2 study (Study 2) were set at 5 and $10 \mathrm{mg} /$ day based on the simulation of receptor occupancy results from positron emission tomography study.
\end{abstract}

Results: Forty-six and fifty-three patients were randomized in Study 1 and Study 2, respectively. The efficacy of enerisant was partially confirmed in Study 1 with ESS; however, the doses were not tolerated, and there were many withdrawals due to adverse events (mainly insomnia, headache, and nausea). The doses in Study 2 were well tolerated, with a lower incidence of adverse events in Study 2 than in Study 1, although the efficacy could not be confirmed with MWT and ESS in Study 2.

Conclusions: The optimal dose of enerisant could not be determined in these two studies. Although enerisant has a favorable pharmacokinetic profile, it is thought to have large interindividual variabilities in terms of efficacy and safety, suggesting the necessity of tailored dosage adjustments.

Trial registration: ClinicalTrials.gov identifier: NCT03267303; Registered 30 August 2017 (Study 2). Japic identifier: JapicCTI-142529; Registered 7 May 2014 (Study 1) and JapicCTI-173689; Registered 30 August 2017, https://www.clinicaltrials.jp/cti-user/trial/ShowDirect.jsp?clinicalTrialld=29277 (Study 2).

Keywords: Enerisant, TS-091, Narcolepsy, Histamine, Clinical trial, MWT, ESS

*Correspondence: inoue@somnology.com

1 Japan Somnology Center, Institute of Neuropsychiatry, 5-10-10 Yoyogi, Shibuya-ku, Tokyo 151-0053, Japan

Full list of author information is available at the end of the article

\section{Background}

Narcolepsy is a sleep disorder characterized by a pathologically increased propensity for both sleep onset and rapid eye movement sleep, causing impairment 
of work performance and quality of life [1], as well as sleepiness-related driving accidents. Currently, several drugs, including modafinil/armodafinil, methylphenidate, pemoline, and sodium oxybate, are available for the treatment of narcolepsy. However, these drugs have drawbacks, such as abuse potential, problems in cardiac safety, tolerability, and adherence issues; furthermore, some patients are refractory to these drugs [2]. Therefore, new pharmacotherapies with different mechanisms and improved safety are desirable.

The histamine $\mathrm{H} 3$ receptor has emerged as one of the most promising targets of novel pharmacotherapy for narcolepsy. Histaminergic neurons are located downstream of the orexin system, the dysfunction of which is involved in the mechanism of narcolepsy, and the histamine $\mathrm{H} 3$ receptor in the central nervous system has a critical role in the regulation of sleep-wake cycles by modulating histaminergic tones as an autoreceptor [3]. To date, many histamine $\mathrm{H} 3$ receptor antagonists/ inverse agonists with diverse scaffolds have been synthesized, and some have been tested in clinical trials [4]. Among these, pitolisant was approved for the treatment of excessive daytime sleepiness (EDS) or cataplexy associated with narcolepsy in 2016 in Europe and in 2019 in the United States [5]. There have been no reports on the dose-response relationship of pitolisant for the treatment of EDS or cataplexy in patients with narcolepsy. The drug is approved for a wide range of doses, from 4.5 to $36 \mathrm{mg} /$ day, with recommendations of patient-specific dose adjustments based on efficacy, safety, and drugdrug interaction (DDI) risks. Thus, the appropriate dose of histamine $\mathrm{H} 3$ receptor antagonists/inverse agonists to exert wake-promoting effects and the relationship between histamine $\mathrm{H} 3$ receptor occupancy and efficacy for the treatment of narcolepsy has not been fully established.

Enerisant, [1-(4-\{3-[(2R)-2-methylpyrrolidin-1-yl] propoxy\} phenyl)-1H-pyrazol-4-yl] (morpholin-4-yl) methanone, is an antagonist/inverse agonist of histamine H3 receptor synthesized by Taisho Pharmaceutical Co., Ltd (Tokyo, Japan) [6]. In vitro studies have shown that enerisant is a potent, highly selective, and competitive antagonist for the histamine $\mathrm{H} 3$ receptor, with a more than 3,000-fold selectivity over other histamine receptor subtypes [6]. Notably, enerisant does not have any affinity for $\sigma 1$ receptors, unlike pitolisant [7]. Enerisant is rarely metabolized in humans, and up to $90 \%$ of the dose is excreted as an unchanged form through urine by $48 \mathrm{~h}$ after administration. These findings suggest that DDI do not occur even when enerisant is used in combination with cytochrome P450 (CYP) inhibitors or inducers, unlike other histamine $\mathrm{H} 3$ receptor antagonists [8]. Therefore, it is possible that enerisant has superior pharmacokinetic (PK) profiles than pitolisant. In addition, because of higher receptor selectivity and superior PK profiles, enerisant can be a suitable tool to determine the appropriate dosage of histamine $\mathrm{H} 3$ receptor antagonists/ inverse agonists for the treatment of narcolepsy. Enerisant demonstrated tolerability at doses of 50 and $100 \mathrm{mg}$ for 7 days in a multiple ascending dose (MAD) study of Japanese healthy individuals. In a MAD study conducted on healthy individuals in the United States, tolerability up to $150 \mathrm{mg}$ for 10 days was confirmed [Unpublished data].

The aim of this report was to investigate the optimal dose of enerisant for the treatment of EDS in patients with narcolepsy. In the 1st phase 2 study (Study 1) for patients with narcolepsy, the dose was decided based on the result of a phase 1 study and nonclinical studies, and in the 2nd phase 2 study (Study 2), the dose was chosen according to the results of the histamine $\mathrm{H} 3$ receptor occupancy study using positron emission tomography (PET) ligand on healthy subjects [9].

\section{Methods}

Study design

\section{Study 1}

This multicenter, randomized, placebo-controlled, double-blind, parallel-group comparative phase 2 study was conducted at 19 sites in Japan (Fig. 1a). Study 1 consisted of four consecutive periods: a preobservation period ( 2 weeks), treatment period A (3 weeks), treatment period B (6 weeks), and a postobservation period (1 week). Treatment period A was designed to evaluate the safety and efficacy of enerisant in patients with narcolepsy, whereas treatment period B was designed mainly to evaluate the safety of enerisant. The target sample size of each group (enerisant 25, 50, $100 \mathrm{mg}$, and placebo groups) was set at $12,12,9$, and 12 participants, respectively, for a total of 45 participants, considering that narcolepsy is a rare disease and this was an exploratory study.

\section{Study 2}

Study 2 was designed after Study 1 was completed. This multicenter, randomized, placebo-controlled, doubleblind, parallel-group comparative phase 2 study was conducted at 19 sites in Japan and 4 sites in Korea (Fig. 1b). Study 2 consisted of three consecutive periods: a preobservation period ( 2 weeks), a treatment period (3 weeks), and a postobservation period (1 week). The treatment period was designed to evaluate the safety and efficacy of enerisant in patients with narcolepsy. The target sample size was set at 16 participants/group with a total of 48 participants, considering the feasibility in patients with 


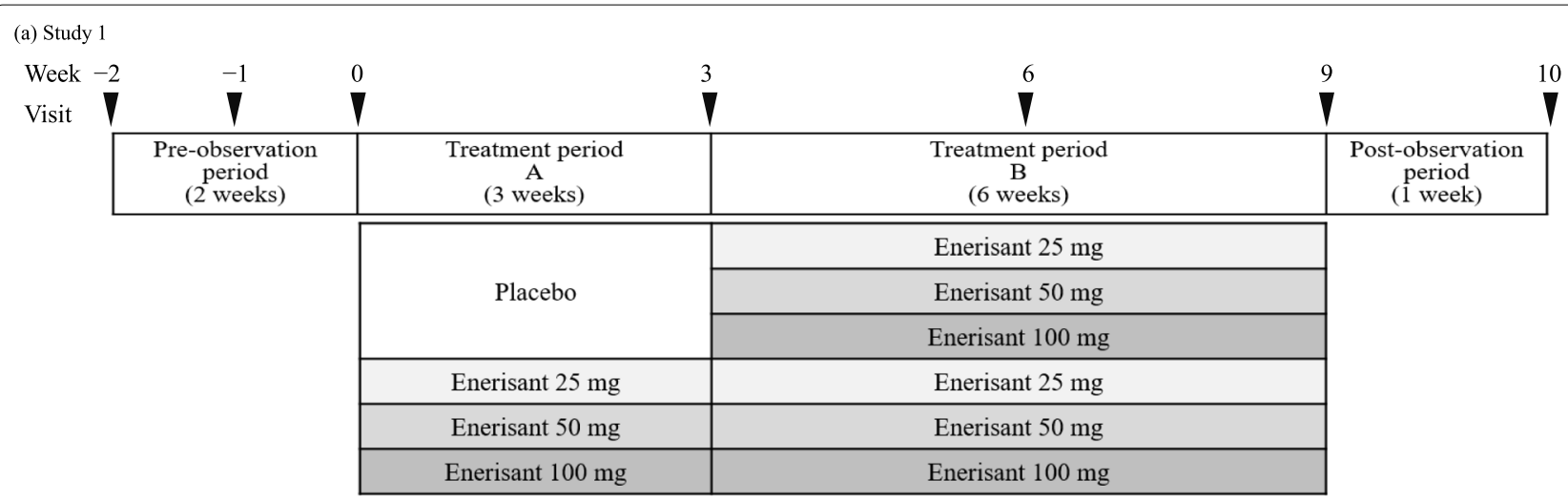

(b) Study 2

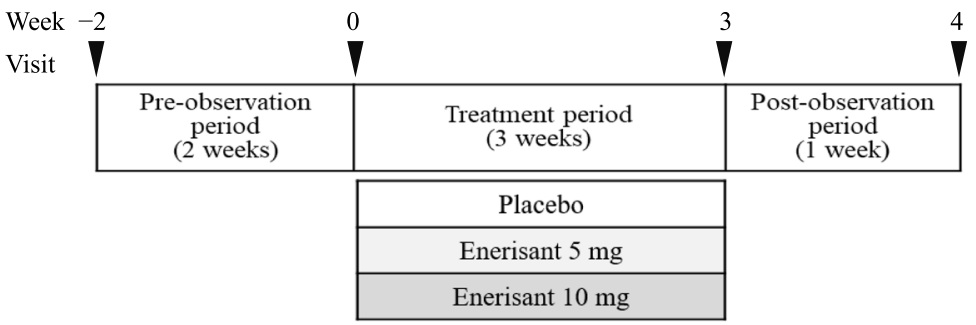

Fig. 1 Study design for Study 1 (a) and Study 2 (b)

the rare disease and the exploratory evaluations of efficacy and safety as the study objective.

\section{Patients}

Study 1

Eligible patients, aged 16-64 years, had received a diagnosis of narcolepsy with/without cataplexy based on the second edition of the International Classification of Sleep Disorders (ICSD-2) [10]. Patients who reported daytime dozing off for at least 4 days and 7 times within 7 days, calculated from their sleep diaries in the preobservation periods, were considered eligible. Exclusion criteria were patients with an apnea hypopnea index of $\geq 15$, periodic limb movement with an arousal index of $\geq 10$ on baseline overnight polysomnography (PSG), sleep latency (SL) of $\geq 20 \mathrm{~min}$ at any session, or mean SL of $\geq 11 \mathrm{~min}$ at 4 sessions on baseline MWT. These criteria items were set with reference to the criteria of the phase 3 study on the use of modafinil in patients with narcolepsy that was previously conducted in Japan, or other relevant studies on pitolisant and JZP-110 (NCT01638403) [11-13]. Patients with complications of organic brain diseases, epilepsy, obstructive respiratory diseases, sleep disorders other than narcolepsy, or significant cardiovascular disease were also excluded. Throughout the study period, the use of drugs that may affect the efficacy and safety assessment of enerisant, such as central nervous system stimulants, anxiolytics, most antidepressants (only clomipramine was allowed to be used at a fixed dose during the study period if the drug was used for cataplexy prior to enrollment in the study), and antihistamines, was prohibited. Only 5 participants used clomipramine during the study (2, 2, 0, and 1 subject in the $25 \mathrm{mg}, 50 \mathrm{mg}, 100 \mathrm{mg}$, and placebo groups, respectively).

\section{Study 2}

Eligible patients were aged 16-64 years at the time of informed consent, with a confirmed diagnosis of narcolepsy type 1 or type 2 based on the third edition of the International Classification of Sleep Disorders (ICSD-3) [14]. Patients with symptoms of EDS occurring at least 4 days and 7 times within 7 days in the preobservation periods were eligible for participation. To enroll patients with a milder severity of narcolepsy, the exclusion criteria on MWT were changed from Study 1; patients with mean $\mathrm{SL}=0 \mathrm{~min}$ at any session or $\geq 20 \mathrm{~min}$ in at least two of the four sessions on baseline MWT were excluded. Other exclusion criteria were patients with an apnea hypopnea index of $\geq 15$, periodic limb movement associated arousal index of $\geq 10$, or total sleep time of $\leq 360 \mathrm{~min}$ on baseline PSG. Patients with complications of organic brain diseases, epilepsy, obstructive respiratory diseases, sleep disorders other than narcolepsy, and significant cardiovascular disease were also excluded. Throughout the study period, the use of drugs that may affect the efficacy and safety assessment of enerisant, 
such as central nervous system stimulants, anxiolytics, antidepressants (including clomipramine), and antihistamines, was prohibited.

\section{Treatments}

Study 1

Patients were randomized in a $1: 1: 1: 1$ ratio to receive enerisant at 25,50 , and $100 \mathrm{mg}$ or placebo once daily in the morning during treatment period A. For treatment period $\mathrm{B}$, patients in the enerisant 25,50 , and $100 \mathrm{mg}$ groups continued to take the same dose, whereas patients in the placebo group were grouped in a 1:1:1 ratio to receive enerisant at 25,50 , or $100 \mathrm{mg}$. The doses were set at 25, 50, and $100 \mathrm{mg}$ based on the safety and pharmacokinetic findings in healthy volunteers confirmed in the phase 1 study [Unpublished data]. Participants were randomized by the stratified block randomization method with the presence or absence of cataplexy as the stratification factor. Randomization was performed by an independent company using a computer-generated list of random numbers. Throughout the study, the patients, site investigators, and raters remained blinded. For safety reasons, allocation to the enerisant $100 \mathrm{mg}$ group was terminated in the middle of the study.

\section{Study 2}

Patients were randomized in a 1:1:1 ratio to receive enerisant at 5 and $10 \mathrm{mg}$ or placebo once daily in the morning. Participants were randomized by the stratified block randomization method with the country of origin as the stratification factor. Randomization was performed by an independent company using a computer-generated list of random numbers. Throughout the study, the patients, site investigators, and raters remained blinded. Adequate efficacy can be expected at 5 and $10 \mathrm{mg}$, according to the results of the intracerebral histamine $\mathrm{H} 3$ receptor occupancy study of healthy individuals [9] (Fig. 2). Based on a PET study using Rhesus monkeys, it was expected that $>90 \%$ occupancy of the $\mathrm{H} 3$ receptor by enerisant promotes arousal. This is consistent with a previous report showing that up to $90 \%$ of human $\mathrm{H} 3$ receptor occupancy by MK-7288 has shown efficacy for EDS due to obstructive sleep apnea [15]. The duration of H3 receptor occupancy at a rate of $90 \%$ was expected to range between 10 and $17 \mathrm{~h}$ with enerisant 5 and $10 \mathrm{mg}$ administration, respectively. Thus, the doses were expected to maintain daytime wakefulness without night-time insomnia.

\section{Outcomes \\ Efficacy}

The efficacy outcomes included the objective and subjective measures of EDS. The primary endpoint for efficacy was a change from baseline to week 3 (the end of period A) in the mean SL of the four MWT sessions in Study 1 and Study 2, respectively. MWT consisted of four 20-min periods with a 2-h interval among respective sessions. This 20-min protocol was the standard method used in multiple previous trials, ensuring an objective assessment of sleepiness in patients with narcolepsy [16]. SL was defined as the time from lights out to the first three consecutive epochs of stage N1 or one epoch of any other stage of sleep as measured by electroencephalogram [17].

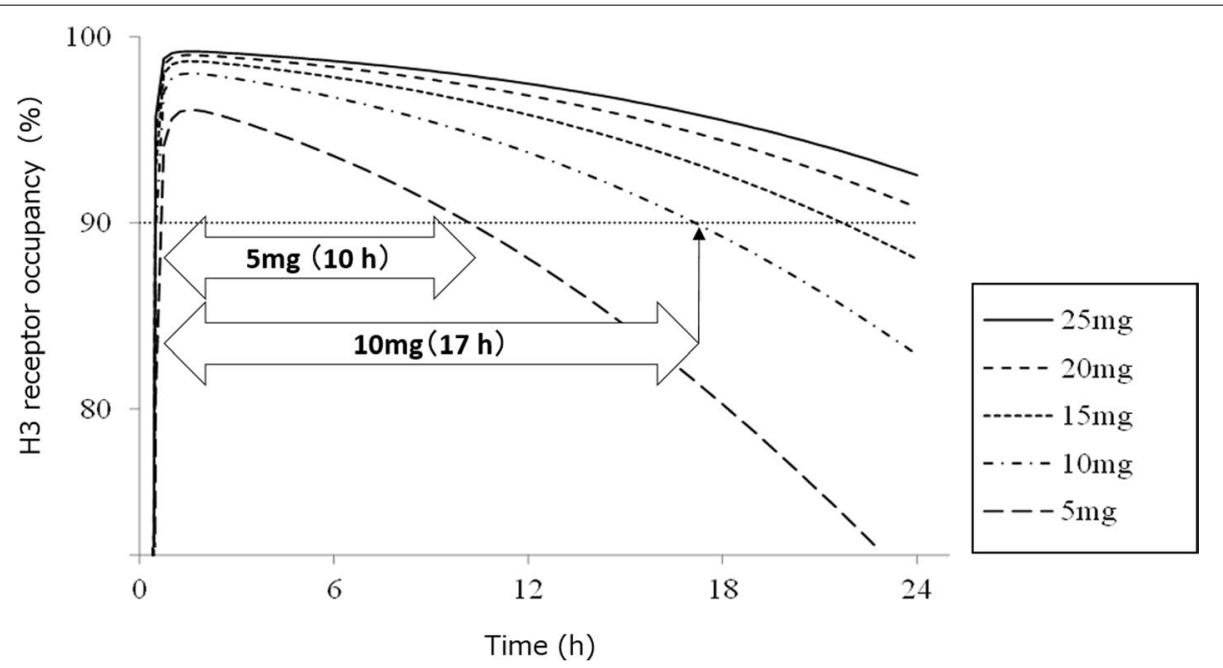

Fig. 2 Simulation of $\mathrm{H} 3$ receptor occupancy after enerisant administration. The time-course of histamine $\mathrm{H} 3$ receptor occupancy after a single oral administration of enerisant was simulated, and the time to maintain $90 \%$ of $\mathrm{H} 3$ receptor occupancy was calculated. In the simulation, pharmacokinetic data obtained from the enerisant single ascending dose study and the pharmacodynamics data obtained from the H3 receptor occupancy study of enerisant [9] were used. Phoenix WinNonlin (ver.6.2) and Microsoft Excel 2010 were used as the analysis software 
The secondary endpoints included changes from the baseline to the end of the study in the Epworth Sleepiness Scale (ESS), a patient-reported measure of EDS, change from baseline to the end of the study in SL of each MWT session, sleep parameters on overnight PSG at the end of the study, and the weekly number of episodes of narcolepsy-related symptoms (i.e., sleep paralysis and cataplexy) reported in patients' sleep diaries.

\section{Safety}

The following safety endpoints were assessed: adverse events (AEs), body weight, laboratory tests, vital signs, 12-lead electrocardiogram (ECG), suicidality evaluated using Columbia-Suicide Severity Rating Scale (C-SSRS), and dependency evaluated using a dependency questionnaire.

\section{Statistics}

For both studies, the full analysis set (FAS) was used as the primary analysis set. Regarding the secondary analysis set, the per protocol set (PPS) was used for the efficacy evaluation, whereas the safety analysis set (SAS) was used for the safety evaluation.

The FAS included patients who received at least one dose of the study drug and had at least one set of efficacy data. The PPS included patients without any serious protocol violations who had available primary endpoint data. The SAS included patients who received at least one dose of the study drug.

Patients' demographics and other baseline characteristics (MWT and ESS) were summarized using descriptive statistics. Primary and secondary efficacy endpoint data were presented as mean values and standard deviations. The least-squares mean differences were compared with the placebo, and the associated 95\% confidence intervals were calculated using analysis of covariance with the baseline as the covariate in Study 1 and using analysis of covariance with the baseline and country (Japan or Korea) as covariates in Study 2. Missing data were not imputed, and data were not adjusted for multiplicity. The two-sided significance level was set at 5\%. Statistical analyses were performed using SAS (SAS Institute, Tokyo, Japan) version 9.2 in Study 1 and version 9.4 in Study 2.

\section{Results}

\section{Study population and characteristics} Study 1

Among the 104 study candidates (range for patient recruitment and follow-up: June 14, 2014 to April 6, 2016), 46 were randomized and allocated to the investigational product group (Fig. 3a). The most common reason for screening failures was not meeting eligibility criteria $(n=48)$. Among the 46 participants who received the investigational product (FAS), 13 withdrew during treatment period A due to AEs (7 participants in the $25 \mathrm{mg}$ group, 3 in the $50 \mathrm{mg}$ group, and 2 in the $100 \mathrm{mg}$ group) and other reason (1 participant in the placebo group). Among the 33 patients who completed treatment period A, 4 withdrew during treatment period $\mathrm{B}$ due to AEs (2 participants in the placebo/enerisant $50 \mathrm{mg}$ group, and 2 in the placebo/enerisant $100 \mathrm{mg}$ group).

Demographics and the other baseline characteristics of the FAS are summarized by treatment groups (Table 1). No statistically significant difference was observed in any baseline characteristics among the treatment groups. The mean age was $27.2 \pm 5.5$ years, body weight was $63.07 \pm 11.70 \mathrm{~kg}$, body mass index was $23.28 \pm 3.64 \mathrm{~kg} /$ $\mathrm{m}^{2}$, and duration of disease was $1.82 \pm 2.71$ years. The mean SL on MWT was $2.63 \pm 2.00 \mathrm{~min}$, and the ESS score was $18.4 \pm 3.2$, without apparent differences between the groups.

\section{Study 2}

Of the 136 study candidates (range for patient recruitment and follow-up: October 31, 2017 to December 13, 2018), 53 were randomized and allocated to the investigational product group (Fig. 3b). The most common reason for screening failures was not meeting eligibility criteria $(n=70)$. Among the 53 participants who received the investigational product (FAS), 5 withdrew from the study due to AEs (3 participants in the enerisant $5 \mathrm{mg}$ group and 1 in the placebo group) and other reason (1 participant in the placebo group).

Demographic and other baseline characteristics for FAS are summarized for respective treatment groups (Table 1). No statistically significant difference among treatment groups was observed in any baseline variables. The mean age was $27.5 \pm 9.3$ years, body weight was $63.61 \pm 14.24 \mathrm{~kg}$, body mass index was $23.55 \pm 4.49 \mathrm{~kg} /$ $\mathrm{m}^{2}$, and duration of disease was $2.08 \pm 2.56$ years. The percentage of patients diagnosed with narcolepsy type 1 was $37.7 \%$ and that of patients with narcolepsy type 2 was $62.3 \%$. Mean SL on MWT was $5.01 \pm 2.90 \mathrm{~min}$, and the ESS score was $17.3 \pm 3.4$, without apparent differences between the groups.

\section{Efficacy \\ Study 1}

Regarding the primary endpoint, the change in mean $\mathrm{SL}$ on MWT was $0.53 \pm 2.75 \mathrm{~min}$ in the $25 \mathrm{mg}$ group, $0.33 \pm 3.72 \mathrm{~min}$ in the $50 \mathrm{mg}$ group, $-0.16 \pm 2.73 \mathrm{~min}$ in the $100 \mathrm{mg}$ group, and $-0.88 \pm 2.40 \mathrm{~min}$ in the placebo group. No statistically significant difference was observed between the placebo and enerisant groups (Table 2). The MWT outcomes in the narcolepsy subgroups with and 


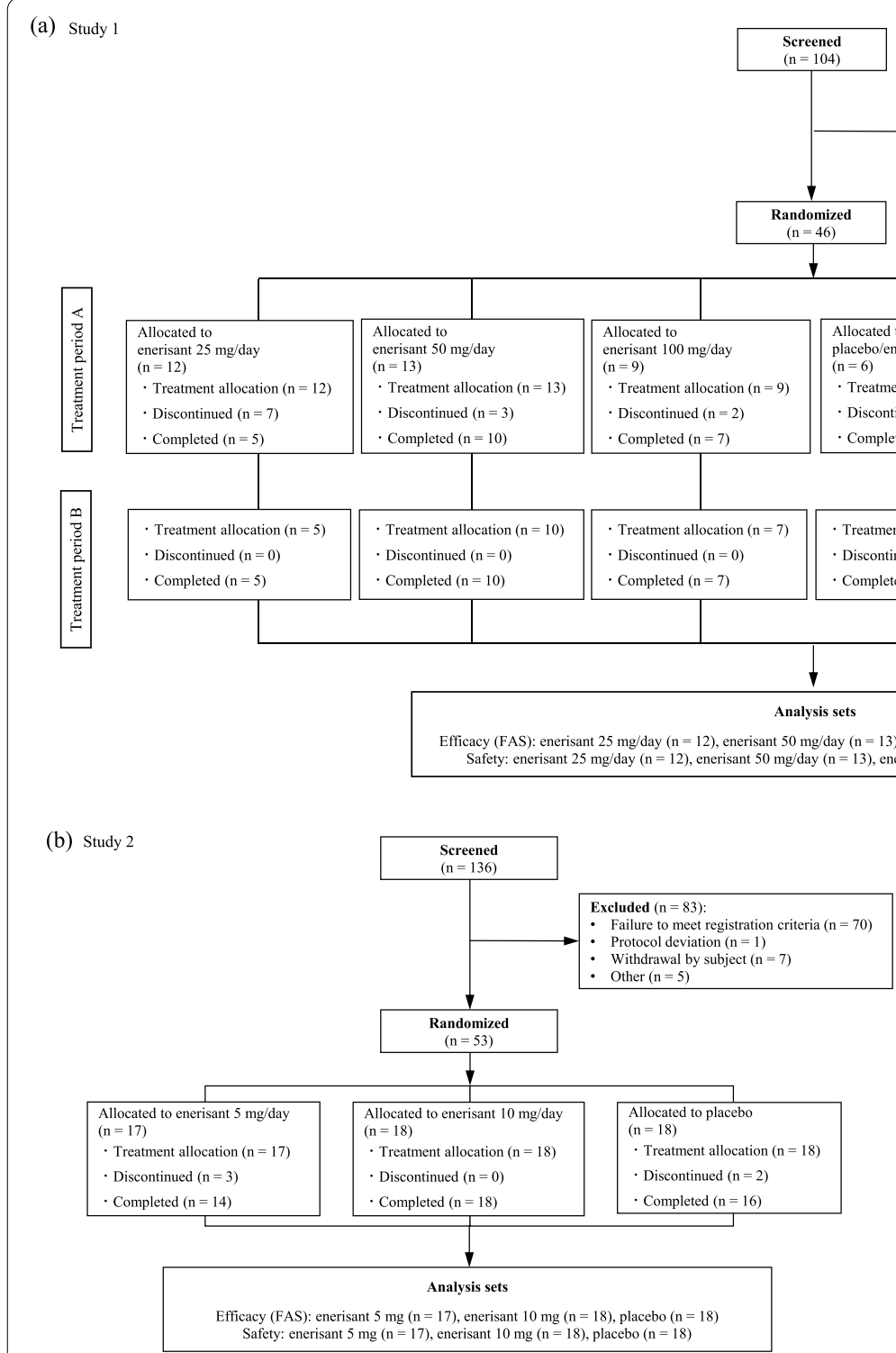

Fig. 3 Disposition of subjects for Study 1 (a) and Study 2 (b)

without cataplexy in Study 1 are provided in Supplementary Table S1.

With regard to one of the secondary efficacy endpoints, the mean change from the baseline total ESS score was $-8.0 \pm 7.0$ in the $25 \mathrm{mg}$ group, $-8.3 \pm 5.8$ in the $50 \mathrm{mg}$ group, $-4.2 \pm 6.2 \mathrm{in}$ the $100 \mathrm{mg}$ group, and $-1.5 \pm 3.5$ in the placebo group (Table 3 ). The total ESS score decreased from week 1 to the end of treatment period $\mathrm{A}$ in the enerisant $50 \mathrm{mg}$ group, and a similar trend was observed in the other enerisant groups. The mean change in the total ESS score was statistically higher in the $50 \mathrm{mg}$ group than in the placebo group ( $p=0.037$ ) (Fig. 4). Results of the other secondary efficacy endpoint, cataplexy incidence, are provided in Supplementary Table S2.

\section{Study 2}

For the primary efficacy endpoint, the change in mean SL on MWT was $0.73 \pm 3.42 \mathrm{~min}$ in the $5 \mathrm{mg}$ group, $0.66 \pm 3.44 \mathrm{~min}$ in the $10 \mathrm{mg}$ group, and $0.22 \pm 4.90 \mathrm{~min}$ in the placebo group (Table 2). The MWT outcomes in patients with narcolepsy type 1 and type 2 in Study 2 are provided in Supplementary Table S2. As a secondary efficacy endpoint, the mean change in the total ESS score was $-4.3 \pm 6.8$ in the $5 \mathrm{mg}$ group, $-3.6 \pm 4.6$ in the $10 \mathrm{mg}$ group, and $-3.9 \pm 5.1$ in the placebo group (Table 3, 


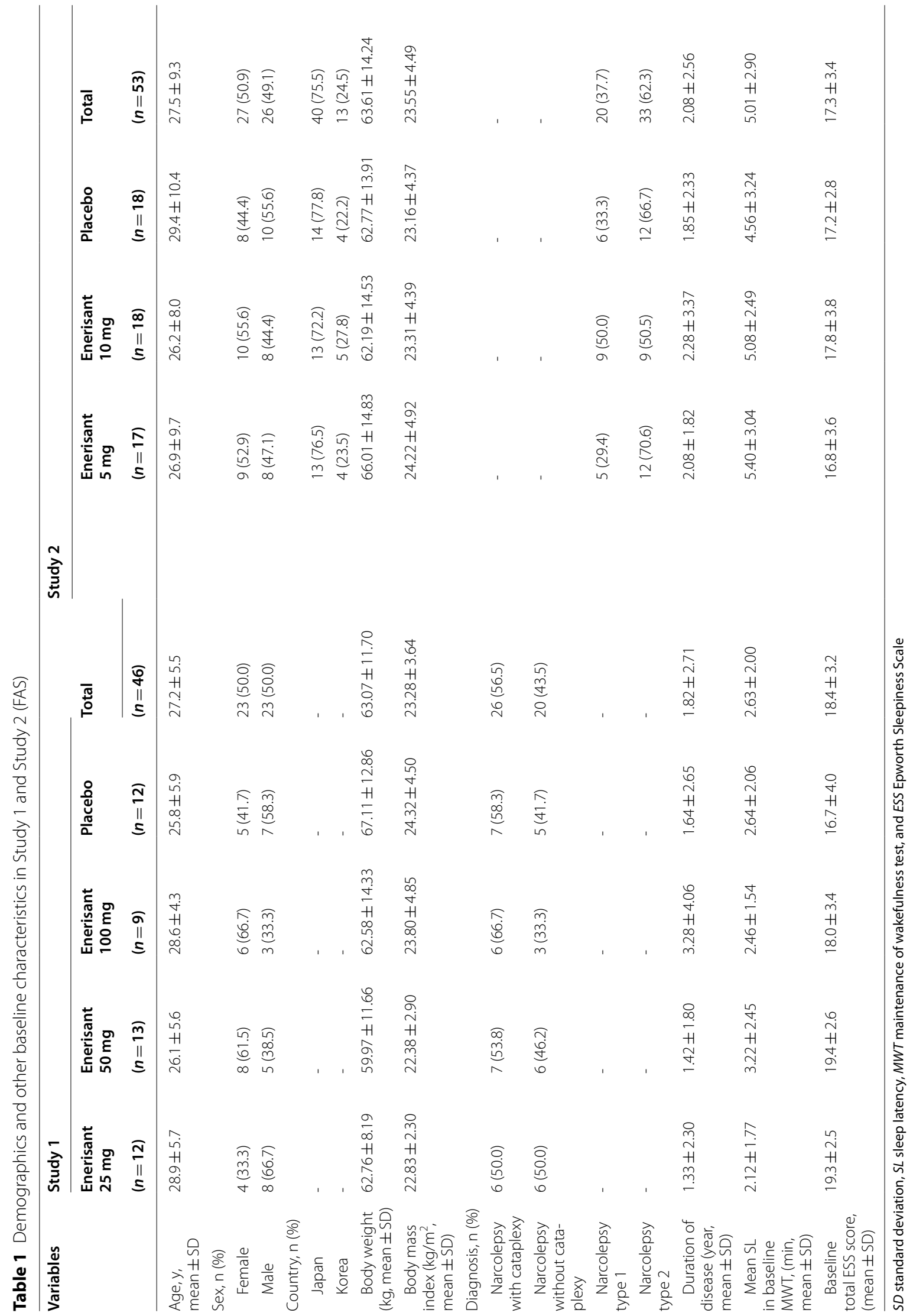


Table 2 Primary endpoint outcomes: MWT changes from baseline in Study 1 and Study 2

\begin{tabular}{|c|c|c|c|c|c|c|c|}
\hline \multirow[t]{2}{*}{ Group } & \multicolumn{4}{|l|}{ Study 1} & \multicolumn{3}{|l|}{ Study 2} \\
\hline & $\begin{array}{l}\text { Enerisant } \\
25 \mathrm{mg} \\
(n=4)\end{array}$ & $\begin{array}{l}\text { Enerisant } \\
50 \mathrm{mg} \\
(n=10)\end{array}$ & $\begin{array}{l}\text { Enerisant } \\
100 \mathrm{mg} \\
(n=7)\end{array}$ & $\begin{array}{l}\text { Placebo } \\
(n=11)\end{array}$ & $\begin{array}{l}\text { Enerisant } \\
5 \mathrm{mg} \\
(n=14)\end{array}$ & $\begin{array}{l}\text { Enerisant } \\
10 \mathrm{mg} \\
(n=18)\end{array}$ & $\begin{array}{l}\text { Placebo } \\
(n=16)\end{array}$ \\
\hline $\begin{array}{l}\text { SL at baseline } \\
\text { (min) }\end{array}$ & $2.12 \pm 1.77$ & $3.22 \pm 2.45$ & $2.46 \pm 1.54$ & $2.64 \pm 2.06$ & $5.40 \pm 3.04$ & $5.08 \pm 2.49$ & $4.56 \pm 3.24$ \\
\hline SL at week 3 (min) & $3.50 \pm 4.69$ & $3.80 \pm 4.52$ & $2.53 \pm 1.85$ & $1.65 \pm 1.98$ & $5.43 \pm 4.41$ & $5.74 \pm 4.73$ & $4.84 \pm 5.20$ \\
\hline $\begin{array}{l}\text { Change from } \\
\text { baseline to week } \\
3 \text { (min) }\end{array}$ & $0.53 \pm 2.75$ & $0.33 \pm 3.72$ & $-0.16 \pm 2.73$ & $-0.88 \pm 2.40$ & $0.73 \pm 3.42$ & $0.66 \pm 3.44$ & $0.22 \pm 4.90$ \\
\hline $\begin{array}{l}\text { Difference } \\
\text { compared with } \\
\text { placebo [ } 95 \% \mathrm{Cl}]\end{array}$ & $\begin{array}{l}1.54 \\
{[-2.00,-5.08]}\end{array}$ & $\begin{array}{l}1.50 \\
{[-1.19,-4.18]}\end{array}$ & $\begin{array}{l}0.77 \\
{[-2.16,-3.70]}\end{array}$ & - & $\begin{array}{l}0.43 \\
{[-2.45,-3.31]}\end{array}$ & $\begin{array}{l}0.41 \\
{[-2.30,-3.13]}\end{array}$ & - \\
\hline$p$ value & 0.380 & 0.263 & 0.594 & & 0.765 & 0.761 & \\
\hline
\end{tabular}

mean $\pm S D$

Cl confidence interval, SD standard deviation, SL sleep latency, MWT maintenance of wakefulness test

Table 3 Secondary endpoint outcomes: ESS changes from baseline in Study 1 and Study 2

\begin{tabular}{|c|c|c|c|c|c|c|c|}
\hline \multirow[t]{2}{*}{ Group } & \multicolumn{4}{|l|}{ Study 1} & \multicolumn{3}{|l|}{ Study 2} \\
\hline & $\begin{array}{l}\text { Enerisant } \\
25 \mathrm{mg} \\
(n=11)\end{array}$ & $\begin{array}{l}\text { Enerisant } \\
50 \mathrm{mg} \\
(n=13)\end{array}$ & $\begin{array}{l}\text { Enerisant } \\
100 \mathrm{mg} \\
(n=9)\end{array}$ & $\begin{array}{l}\text { Placebo } \\
(n=12)\end{array}$ & $\begin{array}{l}\text { Enerisant } \\
5 \mathrm{mg} \\
(n=16)\end{array}$ & $\begin{array}{l}\text { Enerisant } \\
10 \mathrm{mg} \\
(n=18)\end{array}$ & $\begin{array}{l}\text { Placebo } \\
(n=17)\end{array}$ \\
\hline Baseline & $19.3 \pm 2.5$ & $19.4 \pm 2.6$ & $18.0 \pm 3.4$ & $16.7 \pm 4.0$ & $16.8 \pm 3.6$ & $17.8 \pm 3.8$ & $17.2 \pm 2.8$ \\
\hline Week $3^{a}$ & $11.2 \pm 5.5$ & $11.1 \pm 5.4$ & $13.8 \pm 4.8$ & $15.2 \pm 5.4$ & $12.7 \pm 7.6$ & $14.2 \pm 4.8$ & $13.2 \pm 5.4$ \\
\hline $\begin{array}{l}\text { Change from } \\
\text { baseline to } \\
\text { week } 3^{\mathrm{a}}\end{array}$ & $-8.0 \pm 7.0$ & $-8.3 \pm 5.8$ & $-4.2 \pm 6.2$ & $-1.5 \pm 3.5$ & $-4.3 \pm 6.8$ & $-3.6 \pm 4.6$ & $-3.9 \pm 5.1$ \\
\hline $\begin{array}{l}\text { Difference } \\
\text { compared with } \\
\text { placebo [95\% } \\
\mathrm{Cl}]\end{array}$ & $-4.7[-9.4,-0.0]$ & $-4.8[-9.4,--0.3]$ & $-1.8[-6.6,-3.0]$ & - & $-0.5[-4.3,-3.4]$ & $0.5[-3.3,-4.3]$ & - \\
\hline$p$ value & 0.050 & $0.037^{*}$ & 0.463 & & 0.811 & 0.794 & \\
\hline
\end{tabular}

mean \pm SD

SD standard deviation, Cl confidence interval, ESS, Epworth Sleepiness Scale

${ }^{a}$ Includes data from subjects who discontinued before the completion of 3 weeks of dosing

Fig. 4). In the $5 \mathrm{mg}$ and $10 \mathrm{mg}$ groups, there was no statistically significant difference compared with the placebo group in either mean SL on MWT or ESS score. Results of the other secondary efficacy endpoint, cataplexy incidence, are provided in Supplemental Table S2.

\section{Safety}

Study 1

In treatment period A, AEs were reported in $83.3 \%$ (10/12), 69.2\% (9/13), $100.0 \%$ (9/9), and $41.7 \%(5 / 12)$ of the participants in the $25 \mathrm{mg}, 50 \mathrm{mg}, 100 \mathrm{mg}$, and placebo groups, respectively (Table 4). There was a significant difference in the incidence rate of AEs among the treatment groups $(p=0.021)$. The most common AEs were insomnia-related in all the enerisant groups. In treatment period A, insomnia-related AEs were reported by $58.3 \%(7 / 12), 30.8 \%(4 / 13), 88.9 \%(8 / 9)$, and $8.3 \%$ $(1 / 12)$ of the participants in the $25 \mathrm{mg}, 50 \mathrm{mg}, 100 \mathrm{mg}$, and placebo groups, respectively. Other common AEs (those reported by at least 2 patients in any treatment group) were headache [25.0\% (3/12) in the $25 \mathrm{mg}$ group, $30.8 \%(4 / 13)$ in the $50 \mathrm{mg}$ group, $22.2 \%(2 / 9)$ in the $100 \mathrm{mg}$ group, and $0 \%(0 / 12)$ in the placebo group] and nausea $[25.0 \%(3 / 12)$ in the $25 \mathrm{mg}$ group, $7.7 \%(1 / 13)$ in the $50 \mathrm{mg}$ group, $22.2 \%(2 / 9)$ in the $100 \mathrm{mg}$ group, and $0 \%(0 / 12)$ in the placebo group]. There was no dosedependent increase in the incidence of these AEs. AEs leading to discontinuation in treatment period $\mathrm{A}$ were 


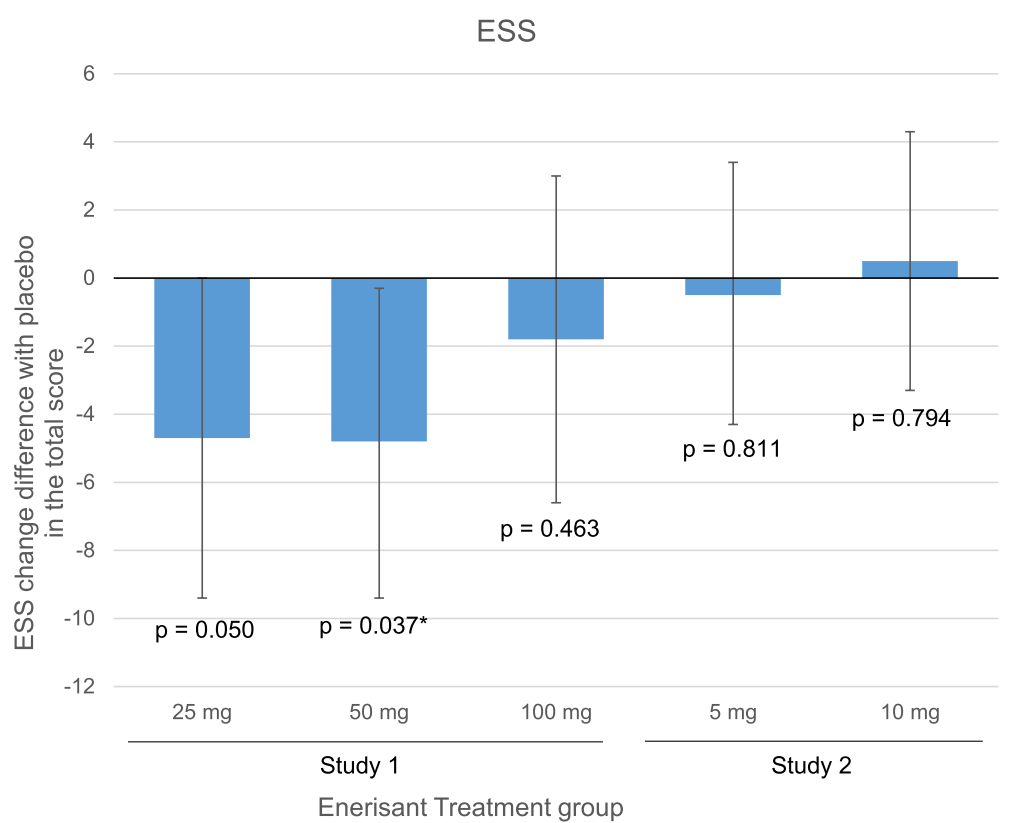

Fig. 4 Secondary endpoint outcomes: total ESS score changes in Study 1 and Study 2. 95\% confidence interval

Table 4 Adverse events in Study 1 and Study 2

\begin{tabular}{|c|c|c|c|c|c|c|c|}
\hline \multirow[t]{2}{*}{ Group } & \multicolumn{4}{|l|}{ Study 1} & \multicolumn{3}{|l|}{ Study 2} \\
\hline & $\begin{array}{l}\text { Enerisant } 25 \mathrm{mg} \\
(n=12)\end{array}$ & $\begin{array}{l}\text { Enerisant } 50 \mathrm{mg} \\
(n=13)\end{array}$ & $\begin{array}{l}\text { Enerisant } 100 \mathrm{mg} \\
(n=9)\end{array}$ & $\begin{array}{l}\text { Placebo } \\
(n=12)\end{array}$ & $\begin{array}{l}\text { Enerisant } 5 \mathrm{mg} \\
(n=17)\end{array}$ & $\begin{array}{l}\text { Enerisant } 10 \mathrm{mg} \\
(n=18)\end{array}$ & $\begin{array}{l}\text { Placebo } \\
(n \mathrm{~h} 18)\end{array}$ \\
\hline Any AE & $10(83.3)$ & $9(69.2)$ & $9(100.0)$ & $5(41.7)$ & $12(70.6)$ & $9(50.0)$ & $5(27.8)$ \\
\hline Serious AEs & 0 & 0 & 0 & 0 & 0 & 0 & 0 \\
\hline Discontinuations due to AEs & $7(58.3)$ & $3(23.1)$ & $2(22.2)$ & 0 & $3(17.6)$ & 0 & $1(5.6)$ \\
\hline \multicolumn{8}{|c|}{ Most common AEs (> 10\% of patients in any group) } \\
\hline Headache & $3(25.0)$ & $4(30.8)$ & $2(22.2)$ & 0 & $4(23.5)$ & $3(16.7)$ & $1(5.6)$ \\
\hline Nausea & $3(25.0)$ & $1(7.7)$ & $2(22.2)$ & 0 & $2(11.8)$ & $2(11.1)$ & $2(11.1)$ \\
\hline Insomnia ${ }^{a}$ & $7(58.3)$ & $4(30.8)$ & $8(88.9)$ & $1(8.3)$ & $4(23.5)$ & $3(16.7)$ & 0 \\
\hline Dizziness & 0 & $1(7.7)$ & 0 & 0 & $3(17.6)$ & 0 & 0 \\
\hline Dysmenorrhea & 0 & 0 & 0 & 0 & 0 & $2(11.1)$ & 0 \\
\hline Palpitations & $1(8.3)$ & $2(15.4)$ & 0 & $1(8.3)$ & 0 & 0 & 0 \\
\hline Nasopharyngitis & 0 & 0 & 0 & $2(16.7)$ & 0 & $1(5.6)$ & 0 \\
\hline Parosmia & $2(16.7)$ & 0 & 0 & 0 & 0 & 0 & 0 \\
\hline
\end{tabular}

${ }^{a}$ MedDRA PT: insomnia, initial insomnia, and middle insomnia

$A E$ adverse event

reported by $58.3 \%$ (7/12), $23.1 \%$ (3/13), $22.2 \%$ (2/9), and $0 \%(0 / 12)$ of the participants in the $25 \mathrm{mg}, 50 \mathrm{mg}$, $100 \mathrm{mg}$, and placebo groups, respectively. From these results, it was speculated that there was a tolerability problem with enerisant. In particular, independent data monitoring of the first 23 patients revealed that many of the participants showing insomnia-related AEs were in the $100 \mathrm{mg}$ group. Given this, we decided not to continue allocation to the $100 \mathrm{mg}$ group. However, AEs leading to death and other severe AEs were not reported in this study, and all of the AEs were mild to moderate in severity (data not shown). Additionally, in other safety variables (laboratory test values, vital signs, 12-lead ECG, and C-SSRS), there were no clinically significant abnormalities or notable trends after dosing. 


\section{Study 2}

AEs were reported by $70.6 \%$ (12/17), 50.0\% (9/18), and $27.8 \%(5 / 18)$ of the participants in the $5 \mathrm{mg}, 10 \mathrm{mg}$, and placebo groups, respectively (Table 4 ). The most common AEs (those reported by at least 2 participants in any treatment group) were insomnia-related (4 participants in the $5 \mathrm{mg}$ group and 3 in the $10 \mathrm{mg}$ group), headache (4 participants in the $5 \mathrm{mg}$ group, 3 in the $10 \mathrm{mg}$ group, and 1 in the placebo group), nausea ( 2 participants each in the $5 \mathrm{mg}, 10 \mathrm{mg}$, and placebo groups), dizziness (3 participants in the $5 \mathrm{mg}$ group), and dysmenorrhea (2 participants in the $10 \mathrm{mg}$ group). AEs leading to discontinuation of the study drugs were reported by $17.6 \%$ $(3 / 17)$ and $5.6 \%(1 / 18)$ of the participants in the $5 \mathrm{mg}$ and placebo groups, respectively. AEs leading to death and other severe AEs were not reported. All AEs were mild to moderate in severity (data not shown). Additionally, in other safety variables (laboratory test values, vital signs, 12-lead ECG, and C-SSRS), there were no clinically significant abnormalities or notable trends after dosing. Overall, enerisant at doses of 5 and $10 \mathrm{mg}$ was well tolerated, and its safety was confirmed.

\section{Discussion}

Two phase 2 dose-finding studies were conducted to evaluate the efficacy and safety of enerisant in patients with narcolepsy. The efficacy of enerisant was partially confirmed in Study 1, which used higher doses $(25,50$, and $100 \mathrm{mg} /$ day), but could not be confirmed in Study 2, which used lower doses (5 and $10 \mathrm{mg} /$ day). The higher doses were not sufficiently tolerated, and there were many withdrawals due to AEs (mainly insomnia, headache, and nausea). In contrast, in Study 2, both doses (5 and $10 \mathrm{mg} /$ day) were well tolerated, with a lower incidence of AEs reported in Study 2 than in Study 1.

In Study 1, the highest dose was set at $100 \mathrm{mg}$, because it was tolerated in a previous MAD study conducted on healthy adults, and the lowest dose was set at $25 \mathrm{mg}$, as the estimated potential effective dose from the results of nonclinical pharmacology studies conducted on cynomolgus monkeys [unpublished data]. Contrary to the results of the MAD study, none of the $25-100 \mathrm{mg} /$ day doses were sufficiently tolerated in patients with narcolepsy. The AEs were similar between the MAD study and Study 1, and insomnia was the most frequently reported AE. However, the frequency of insomnia and the rate of withdrawal due to the occurrence of AEs (overall) were much higher in Study 1 than in the MAD study.

Although the precise reason for the higher frequency of insomnia with enerisant treatment in patients with narcolepsy than in healthy subjects is unknown, it may be ascribed to a difference in the activities of histaminergic neurons. Indeed, it has been reported that patients with narcolepsy had a $94 \%$ greater number of tuberomammillary nucleus histaminergic neurons compared with nonnarcoleptic controls [18]. Given this, it is conceivable that sensitivity to $\mathrm{H} 3$ receptor antagonists may differ between patients with narcolepsy and healthy adults, possibly leading to the difference in tolerability to enerisant.

In Study 1, the changes in the ESS score among all the enerisant groups seemed to be larger, and a significant difference compared with the placebo group was seen in the $50 \mathrm{mg} /$ day group, suggesting that enerisant has the potential to improve daytime sleepiness in patients with narcolepsy. On the other hand, the changes in mean SL on MWT in the enerisant groups were small and did not show statistical difference compared with those in the placebo group. Discrepancies between these two endpoints have been shown in many reports $[19,20]$. MWT is an objective index of the inability to maintain wakefulness, whereas ESS is a subjective self-reported index of sleepiness [19]. Thus, differences in the characteristics of these measures might have contributed to the discrepancy in the results. ESS was authorized as a primary endpoint in the EU pitolisant study [21]; thus, ESS could be reliable to evaluate daytime sleepiness in clinical trials with $\mathrm{H} 3$ receptor antagonists. Notably, the average baseline MWT in Study 1 was 2.6 min, which is lower than the previously reported baseline SLs on MWT in the modafinil and pitolisant clinical trials [21, 22]. Therefore, it is possible that patients with more severe symptoms were recruited in Study 1 than in the previously conducted trials, possibly hampering efficacy detection of enerisant due to the "floor effect."

When we planned Study 2, the doses were set at a much lower level based on the low tolerability in Study 1 , and patients with relatively larger SLs on MWT were included, taking the floor effect into consideration. In particular, we simulated the doses in Study 2 based on the time-course of cerebral H3 receptor occupancy of enerisant in healthy adults obtained in a PET study [9]. The receptor occupancy simulation employed in Study 2 indicated that the dose of $5 \mathrm{mg}$ occupies $\mathrm{H} 3$ receptor by more than $90 \%$ for $10 \mathrm{~h}$ after administration. Likewise, the maximum dose was set at $10 \mathrm{mg}$, which occupies $\mathrm{H} 3$ receptor by more than $90 \%$ for $17 \mathrm{~h}$. Thus, $5 \mathrm{mg}$ was speculated not to induce insomnia theoretically, and AEs, including insomnia, were expected to be markedly reduced at $10 \mathrm{mg}$. According to our simulation, all doses used in Study 1 were estimated to occupy $\mathrm{H} 3$ receptor by more than $90 \%$ for $24 \mathrm{~h}$, which might have led to the high incidence of insomnia, even at the lowest dose ( $25 \mathrm{mg} /$ day).

As expected, there was a reduction in the frequency of AEs (including insomnia) and fewer withdrawals 
due to AEs in Study 2 than in Study 1, despite the small number of patients in both the $5 \mathrm{mg}$ and $10 \mathrm{mg}$ groups with insomnia-related AEs. On the other hand, although some patients showed some improvement in MWT or ESS, the efficacy expected from the receptor occupancy simulation was not observed in either of these two measures in Study 2. The variations in the efficacy and safety of enerisant among patients might indicate the existence of individual sensitivity to this drug. Given this, both efficacy and tolerability could not be fully predicted only from the receptor occupancy simulation of enerisant, and individual differences in patients need to be considered.

As enerisant is rarely metabolized by CYP, individual differences in its plasma concentration have been speculated to be relatively low [8]. Therefore, we initially speculated that the optimal fixed dose for patients with narcolepsy would be in the range of 5-100 mg. However, contrary to our hypothesis, the efficacy and safety were significantly different among patients, including differences in tolerability between healthy adults and patients with narcolepsy. As such, the optimal dose could not be determined in the fixed-dose studies.

As for pitolisant, the approved dose ranges widely from 4.5 to $36 \mathrm{mg}$, and patient-specific dose adjustment is recommended considering the efficacy, safety, and influences of drugs metabolized by CYPs [23]. Therefore, interindividual variabilities in terms of efficacy and safety may be common between $\mathrm{H} 3$ receptor antagonists, independent of their pharmacological or pharmacokinetic profiles. In addition, doses of pitolisant up to $36 \mathrm{mg}$, taken once daily, show efficacy and are tolerated [24]. In our study, sufficient efficacy and tolerability at higher doses of enerisant were observed in some patients, but any firm conclusions on this aspect cannot be drawn in this study. The differences in the results between pitolisant and enerisant possibly stem from the differences in the study design (e.g., dose-titration design vs. fixed-dose design).

The detailed mechanisms of histamine action remain unclear; however, it is noteworthy that even enerisant, which has a better PK profile than pitolisant, showed large individual differences in efficacy and tolerability. In addition to differences in sensitivity to AEs between healthy adults and patients with narcolepsy, changes in histaminergic neuronal activities may differ even among patients with narcolepsy, both qualitatively and quantitatively. This may explain the large individual differences in the efficacy and safety of $\mathrm{H} 3$ receptor antagonists. Because $\mathrm{H} 3$ receptor antagonists exert their effect by increasing histamine release and subsequent stimulation of postsynaptic $\mathrm{H} 1$ receptor, the determination of $\mathrm{H} 1$ receptor occupancy with released histamine by $\mathrm{H} 3$ receptor antagonists would help clarify this issue.

As the first limitation, the present study possibly had sampling bias coming from the additional inclusion/exclusion criteria items (i.e. the weekly frequency of daytime dozing off or SL on MWT at the baseline) for precisely evaluating the effect of study drugs. As the second limitation, especially in Study 1 many participants discontinued treatment due to AEs, and the limited number of patients who underwent post-treatment MWT made it difficult to interpret the results on efficacy.

\section{Conclusions}

In the present two studies, it was not possible to determine the optimal dose of enerisant for the treatment of EDS in patients with narcolepsy. As enerisant showed large interindividual variability in its efficacy and safety despite its favorable PK profile, tailored dosage adjustments based on individual efficacy and safety would be required. We hope that future studies reveal the efficacy and safety of enerisant for the treatment of narcolepsy and other neuropsychiatric disorders for which $\mathrm{H} 3$ receptor antagonists can be indicated.

\section{Abbreviations \\ AASM: American Academy of Sleep Medicine; AE: Adverse event; C-SSRS: Columbia-Suicide Severity Rating Scale; CYP: Cytochrome P450; DDI: Drug- drug interaction; ECG: Electrocardiogram; EDS: Excessive daytime sleepiness; ESS: Epworth Sleepiness Scale; FAS: Full analysis set; ICSD-2: The second edition of the International Classification of Sleep Disorders; ICSD-3: The third edition of the International Classification of Sleep Disorders; MAD: Multiple ascending dose; MWT: Maintenance of wakefulness test; PET: Positron emis- sion tomography; PK: Pharmacokinetic; PPS: Per protocol set; PSG: Polysom- nography; RO: Receptor occupancy; SAD: Single ascending dose; SAS: Safety analysis set; SD: Standard deviation; SL: Sleep latency; TST: Total sleep time; WASO: Wake time after sleep onset.}

\section{Supplementary Information}

The online version contains supplementary material available at https://doi. org/10.1186/s12888-022-03785-7.

Additional file 1: Table S1. The MWT outcomes in the narcolepsy subgroups with and without cataplexy in Study 1. Table S2. Weekly incidence of cataplectic episodes in Study 1 and Study 2. Table S3. The MWT outcomes in patients with narcolepsy type 1 and type 2 in Study 2.

Additional file 2. List of the ethics committees.

\section{Acknowledgements}

We thank the participants of this study and the study investigators of the 32 sites: Yoyogi Sleep Disorder Center, Osaka Kaisei Hospital, Hannan Hospital, Ehime University Hospital, Kochi Kagamigawa Hospital, Kurume University Hospital, Nakamura Clinic, National Center of Neurology and Psychiatry, Gifu Mates Sleep Clinic, You Ariyoshi Sleep Clinic, Toyohashi Mates Sleep Treatment Clinic, Akita University Hospital, Iwata Mates Sleep Disorders Treatment Clinic, Kirigaoka Tsuda Hospital, Otsuki Sleep Clinic, Junwakai Memorial Hospital, Ota Memorial Center, Aichi Medical University Hospital, Inoue Hospital, Kuwamizu Hospital, Fukuoka Urasoe Clinic, Good-Sleep Clinic, Good-Sleep Omori Clinic, 
Tanaka Sleep Clinic, Kyotani Clinic, Takaoka Clinic, Hirasawa Sleep Mental Clinic, Kotorii Isahaya Hospital, The Catholic University of Korea St. Vincent Hospital, Samsung Medical Center, Seoul National University Hospital, and KyungHee University at Gangdong.

We also thank Hiroo Kuwahara and Tomoko Yagi for the central scoring of MWT data, Tetsuya Suhara and Yasuyuki Kimura for consultation of the receptor occupancy study, Shigeyuki Chaki for reviewing the manuscript, and MARUZEN-YUSHODO Co., Ltd. ( https://kw.maruzen.co.jp/kousei-honyaku/ ) for the English language editing.

This study was sponsored by Taisho Pharmaceutical Co., Ltd.

\section{Authors' contributions}

Study design, conduct, and data collection: $\mathrm{YI}, \mathrm{MU}, \mathrm{HU}, \mathrm{KO}, \mathrm{HO}, \mathrm{IK}, \mathrm{IN}$, and $\mathrm{NU}$. Data analysis and interpretation: all authors. Writing and/or reviewing the manuscript: Yl, MU, HU, KO, IN, and NU. Final approval of the manuscript for submission: all authors.

\section{Funding}

This study was funded by Taisho Pharmaceutical Co., Ltd. The study sponsor had a role in the design of the study; the collection, analysis, and interpretation of the data; the writing of the report; and the decision to submit the article for publication.

\section{Availability of data and materials}

The data that support the findings of this study are available from Taisho Pharmaceutical Co., Ltd. However, restrictions apply to the availability of these data due to their use under license for the current study as they are not currently publicly available. Data are however available from the authors upon reasonable request and with the permission of Taisho Pharmaceutical Co., Ltd.

\section{Declarations}

\section{Ethics approval and consent to participate}

These two clinical trials have been performed in accordance with the Declaration of Helsinki. The institutional review board of each site approved the study protocol (Additional file 2), and all patients and/or legal guardians provided written informed consent for study participation. This study was conducted following the CONSORT guidelines.

\section{Consent for publication}

Not Applicable.

\section{Competing interests}

Yuichi Inoue reports that he and his department have received research support (grants) from Philips Japan Co., Ltd. and KOIKE Medical Co., Ltd.; in addition, he has provided speaking and consulting services to and received personal fees from Eisai Co., Ltd., provided speaking services and received personal fees from Otsuka Pharmaceutical Co., Ltd., Takeda Pharmaceutical Co., Ltd., Astellas Pharma Inc., and MSD K.K.; and provided consulting services and received personal fees from Taisho Pharmaceutical Co., Ltd. Makoto Uchiyama reports that he and his department have received grants from Astellas Pharma Inc., Eisai Co., Ltd., Meiji Seika Pharma Co., Ltd., Mochida Pharmaceutical Co., Ltd., Merck Sharp \& Dohme, Pfizer Inc., Sanofi S.A., Takeda Pharmaceutical Co., Ltd., and Yoshitomiyakuhin Corporation; in addition, he has provided consulting services and received personal fees from Janssen Pharmaceutical K.K., Kao Corporation, Shionogi \& Co., Ltd., and Taisho Pharmaceutical Co., Ltd. Hideo Umeuchi, Koichi Onishi, Hiroki Ogo, Iwao Kitajima, Isao Matsushita, and Izumi Nishino are employees of Taisho Pharmaceutical Co. Ltd. Naohisa Uchimura reports receiving grants from Eisai Co., Ltd., Otsuka Pharmaceutical Co., Ltd., Merck Sharp \& Dohme, and Takeda Pharmaceutical Co., Ltd.; in addition, he has provided consulting services to and received personal fees from Taisho Pharmaceutical Co., Ltd.

\section{Author details}

${ }^{1}$ Japan Somnology Center, Institute of Neuropsychiatry, 5-10-10 Yoyogi, Shibuya-ku, Tokyo 151-0053, Japan. ${ }^{2}$ Department of Somnology, Tokyo Medical University, 6-7-1 Nishishinjuku, Shinjuku-ku, Tokyo 160-0023, Japan. ${ }^{3}$ Department of Psychiatry, Nihon University School of Medicine, 30-1 Oyaguchi-kamicho, Itabashi, , Tokyo 173-8610, Japan. ${ }^{4}$ Tokyoadachi Hospital, 5-23-20
Hokima, Adachi, Tokyo 121-0064, Japan. ${ }^{5}$ Development Headquarters, Taisho Pharmaceutical Co., Ltd., 3-24-1 Takada, Toshima-Ku, Tokyo 170-8633, Japan. ${ }^{6}$ Department of Neuropsychiatry, Kurume University School of Medicine, 67 Asahi-machi, Kurume, Fukuoka 830-0011, Japan.

Received: 16 July 2021 Accepted: 9 February 2022

Published online: 22 February 2022

\section{References}

1. Ozaki A, Inoue Y, Hayashida K, et al. Quality of life in patients with narcolepsy with cataplexy, narcolepsy without cataplexy, and idiopathic hypersomnia without long sleep time: comparison between patients on psychostimulants, drug-naïve patients and the general Japanese population. Sleep Med. 2012;13(2):200-6. https://doi.org/10.1016/j. sleep.2011.07.014 (Epub 2011 Dec 3 PMID: 22137109).

2. Calik MW. Update on the treatment of narcolepsy: clinical efficacy of pitolisant. Nat Sci Sleep. 2017;9:127-33. https://doi.org/10.2147/NSS. S103462.

3. Esbenshade TA, Browman KE, Bitner RS, et al. The histamine H3 receptor: an attractive target for the treatment of cognitive disorders. $\mathrm{Br} \mathrm{J}$ Pharmacol. 2008;154(6):1166-81. https://doi.org/10.1038/bjp.2008.147.

4. Lebois EP, Jones $\mathrm{CK}$, Lindsley $\mathrm{CW}$. The evolution of histamine $\mathrm{H}_{3}$ antagonists/inverse agonists. Curr Top Med Chem. 2011;11(6):648-60. https://doi.org/10.2174/1568026611109060648 (PMID: 21261594).

5. Barateau L, Dauvilliers Y. Recent advances in treatment for narcolepsy. Ther Adv Neurol Disord. 2019;12:1756286419875622. https://doi.org/ $10.1177 / 1756286419875622$.

6. Hino N, Marumo T, Kotani M, et al. A novel potent and selective histamine $\mathrm{H} 3$ receptor antagonist enerisant: in vitro profiles, in vivo receptor occupancy, and wake-promoting and procognitive effects in rodents. J Pharmacol Exp Ther. 2020;375(2):276-85. https://doi.org/10. 1124/jpet.120.000185 (Epub 2020 Aug 29 PMID: 32862143 ).

7. Riddy DM, Cook AE, Shackleford DM, et al. Drug-receptor kinetics and sigma-1 receptor affinity differentiate clinically evaluated histamine $\mathrm{H} 3$ receptor antagonists. Neuropharmacology. 2019;144:244-55. https:// doi.org/10.1016/j.neuropharm.2018.10.028 (Epub 2018 Oct 22 PMID: 30359639).

8. Terasaka S, Hachiuma K, Mano Y, et al. Drug-drug interaction potential and clinical pharmacokinetics of enerisant, a novel potent and selective histamine H3 receptor antagonist. Xenobiotica. 2021;28:1-10. https://doi.org/10.1080/00498254.2021.1918361 (Epub ahead of print. PMID: 33910470)

9. Kimura Y, Takahata K, Shimazaki T, et al. Pharmacokinetic and pharmacodynamic assessment of histamine $\mathrm{H} 3$ receptor occupancy by enerisant: a human PET study with a novel H3 binding ligand, [11C] TASP457. Eur J Nucl Med Mol Imaging 2021 https://doi.org/10.1007/ s00259-021-05571-1 Epub ahead of print. PMID: 34651222.

10. International Classification of Sleep Disorders. Diagnostic and coding manual. 2nd ed. Westchester: American Academy of Sleep Medicine; 2005.

11. Inoue $Y$, Honda $Y$, Takahashi $Y$, et al. Efficacy and safety of treatment with modafinil in Japanese patients with narcolepsy: results from double blind placebo-controlled study. Jpn J Sleep Med (Suiminiryo). 2007;1(4):85-97 (in Japanese).

12. Doghramji K, Mitler MM, Sangal RB, et al. A normative study of the maintenance of wakefulness test (MWT). Electroencephalogr Clin Neurophysiol. 1997;103(5):554-62. https://doi.org/10.1016/s0013-4694(97) 00010-2 (PMID:9402886; PMCID:PMC2424234).

13. Bogan RK, Feldman N, Emsellem HA, et al. Effect of oral JZP-110 (ADX-N05) treatment on wakefulness and sleepiness in adults with narcolepsy. Sleep Med. 2015;16(9):1102-8. https://doi.org/10.1016/j. sleep.2015.05.013 (Epub 2015 Jun 3 PMID: 26298786).

14. American Academy of Sleep Medicine. International Classification of Sleep Disorders (3rd ed.). Darien: American Academy of Sleep Medicine; 2014.

15. Sun H, MacLeod C, Mostoller K, et al. Early-stage comparative effectiveness: randomized controlled trial with histamine inverse agonist MK-7288 in excessive daytime sleepiness patients. J Clin Pharmacol. 
2013;53(12):1294-302. https://doi.org/10.1002/jcph.182 (Epub 2013 Oct 4 PMID: 24122944)

16. Randomized trial of modafinil for the treatment of pathological somnolence in narcolepsy. US modafinil in Narcolepsy Multicenter Study Group. Ann Neurol. 1998;43(1):88-97. doi: https://doi.org/10.1002/ana. 410430115. PMID: 9450772.

17. Arand D, Bonnet M, Hurwitz T, et al. The clinical use of the MSLT and MWT. Sleep. 2005;28(1):123-44. https://doi.org/10.1093/sleep/28.1.123 (PMID: 15700728).

18. Valko PO, Gavrilov YV, Yamamoto M, et al. Increase of histaminergic tuberomammillary neurons in narcolepsy. Ann Neurol. 2013;74(6):794804. https://doi.org/10.1002/ana.24019 (PMID: 24006291).

19. Sangal RB, Mitler MM, Sangal JM. Subjective sleepiness ratings (Epworth Sleepiness Scale) do not reflect the same parameter of sleepiness as objective sleepiness (maintenance of wakefulness test) in patients with narcolepsy. Clin Neurophysiol. 1999;1 10(12):2131-5. https://doi.org/10.1016/s1388-2457(99)00167-4 (PMID: 10616118).

20. Sauter C, Asenbaum S, Popovic R, et al. Excessive daytime sleepiness in patients suffering from different levels of obstructive sleep apnoea syndrome. J Sleep Res. 2000;9(3):293-301. https://doi.org/10.1046/j. 1365-2869.2000.00211.x (PMID: 11012870).

21. Dauvilliers Y, Bassetti C, Lammers GJ, et al. Pitolisant versus placebo or modafinil in patients with narcolepsy: a double-blind, randomised trial. Lancet Neurol. 2013;12(11):1068-75. https://doi.org/10.1016/S14744422(13)70225-4 (Epub 2013 Oct 7 PMID: 24107292).

22. Fry JM. Treatment modalities for narcolepsy. Neurology. 1998;50(2):S43-8. https://doi.org/10.1212/wnl.50.2_suppl_1.s43 (PMID: 9484423)

23. Romigi A, Vitrani G, Lo Giudice T, et al. Profile of pitolisant in the management of narcolepsy: design, development, and place in therapy. Drug Des Devel Ther. 2018;12:2665-75. https://doi.org/10.2147/DDDT. S101145.PMID:30214155;PMCID:PMC61 24464.

24. Davis CW, Kallweit U, Schwartz JC, et al. Efficacy of pitolisant in patients with high burden of narcolepsy symptoms: pooled analysis of short-term, placebo-controlled studies. Sleep Med. 2021;81:210-7. https://doi.org/10.1016/j.sleep.2021.02.037 (Epub 2021 Feb 24 PMID: 33721598).

\section{Publisher's Note}

Springer Nature remains neutral with regard to jurisdictional claims in published maps and institutional affiliations.

- fast, convenient online submission

- thorough peer review by experienced researchers in your field

- rapid publication on acceptance

- support for research data, including large and complex data types

- gold Open Access which fosters wider collaboration and increased citations

- maximum visibility for your research: over $100 \mathrm{M}$ website views per year

At BMC, research is always in progress.

Learn more biomedcentral.com/submissions 